\title{
A Study on Wind Frequency Control under High Wind Penetration on an NPCC System Model
}

\author{
Yin Lei ${ }^{1}$, Yong Liu ${ }^{1}$, Geifei Kou ${ }^{1}$, Bin Wang ${ }^{1}$, Changgang $\mathrm{Li}^{1}$, Kai Sun ${ }^{1}$, Senior Member, IEEE, Yilu Liu ${ }^{1,2}$, Fellow, \\ IEEE, Kevin Tomsovic ${ }^{1}$, Fellow, IEEE, Joe Chow ${ }^{3}$, Fellow, IEEE \\ ${ }^{1}$ The University of Tennessee \\ Knoxville, TN \\ ${ }^{2}$ Oak Ridge National Laboratory \\ Oak Ridge, TN \\ ${ }^{3}$ Rensselaer Polytechnic Institute \\ Troy, New York \\ ylei6@utk.edu, liu@utk.edu
}

\begin{abstract}
Increased penetration levels of wind generation and retirements of conventional plants have caused concerns about a decline of system inertia and primary frequency response. To evaluate the impact of wind power on the system inertial response, simulation scenarios with different wind penetration levels are developed in PSS ${ }^{\circledR} E$ based on the U.S. Northeast Power Coordinating Council (NPCC) system. A user-defined electrical control model is also introduced to provide inertia and governor control to the doubly-fed induction generator (DFIG)based wind generations. An extreme case of $100 \%$ renewable resources including $90 \%$ wind and $10 \%$ hydro generations is considered in this study and simulation results demonstrate that wind power has significant impact on system inertial response and is also promising in providing primary frequency supports.
\end{abstract}

Index Terms-Inertial response, primary frequency response, variable-speed wind generator, wind frequency control

\section{INTRODUCTION}

Wind generation will play an important role in the total generation mix in future power systems in order to meet the needs of environmental regulations. Due to the different structure and control strategy of a wind turbine, its performance is different from conventional machines. It is crucial to maintain the power system frequency in specified range so that the power system is reliable and secure [1]. For conventional machines, in the first few seconds after a disturbance, the frequency dynamics are dominated by the inertial response of the on-line generation. Synchronous machines inherently contribute some of its stored inertial energy to the grid, reducing the frequency decline and allowing slower local governor actions to stabilize the system frequency [2]. However, most variable-speed wind generation does not exhibit this inertial response due to the lack of synchronization torque. Without special controls, the wind power plant does not participate in primary frequency response either [3].

These issues address a need to let the wind generation provide adequate frequency control. Many researchers have proposed different designs to allow wind power plants to

This work was supported primarily by the Engineering Research Center Program of the National Science Foundation and DOE under NSF Award Number EEC-1041877 and the CURENT Industry Partnership Program. provide capabilities similar to system inertial control and primary frequency response [4]. The work reported here adopts the modern technology of power electronics. Though the steady-state active power delivered to the grid solely depends on the mechanical energy transferred from a wind turbine, the electric power of variable-speed wind generators can be effectively controlled by modern power electronics devices in a fast manner. As a result, wind generation has significant capabilities to engage in frequency regulation when wind penetration is considerably high.

The Northeast Power Coordinating Council (NPCC) region system used in this study lies within the U.S. Eastern Interconnection (EI) and occupies the greater New England region of North America, covering the States of Maine, Vermont, New Hampshire, Massachusetts, New York, Connecticut, Rhode Island, and the Provinces of Ontario, Québec, New Brunswick, Nova Scotia and Prince Edward Island. NPCC also has ties to non-NERC systems in Northern Canada. In terms of load served, NPCC covers $20 \%$ of the Eastern interconnection's total load demand, and $70 \%$ of Canada's entire demand [5].

This paper is structured as follows. Section II provides a detailed demonstration of how the simulation scenarios are built, and the system performances of each case are given. Section III evaluates the impact of wind penetration on inertial response and illustrates the contribution of wind control to the system frequency regulation by comparing different cases. Section IV concludes the study.

\section{MODEL DEVELOPMENT}

The purpose of this paper is to evaluate the wind impact on system inertial response, as well as to study the potential contribution of variable- speed wind generation to frequency regulation using the PSS/E dynamic simulation software. A 700 MW generation trip is simulated in all cases to demonstrate the frequency responses under different conditions. 


\section{A. Base Case without Wind Penetration}

The baseline model of NPCC system used in this study is a reduced model with 140 buses, and 48 machines. The total capacity of NPCC system is about $28 \mathrm{GW}$. Fig. 1 shows the one-line diagram. The PSS/E format of NPCC model is formulated based on the data in the MATLAB Power System Toolbox. Power flow data were formatted into PSS/E raw file directly. However, the dynamic data were formatted with some changes in order to meet the requirements of the reasonable relations among transient reactance and time constants of GENROU type generators. In addition, in order to make the system more realistic, a generic governor model was also added. Fig. 2-3 shows the system response to a generation trip in the base case.

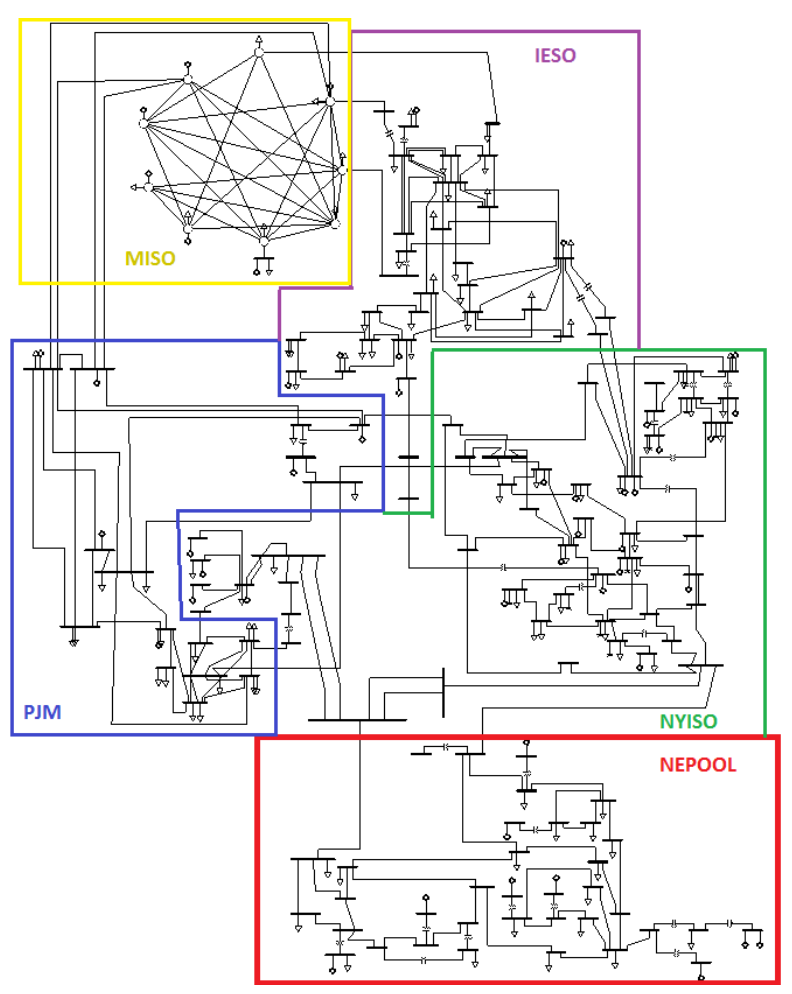

Figure 1. NPCC system one-line diagram

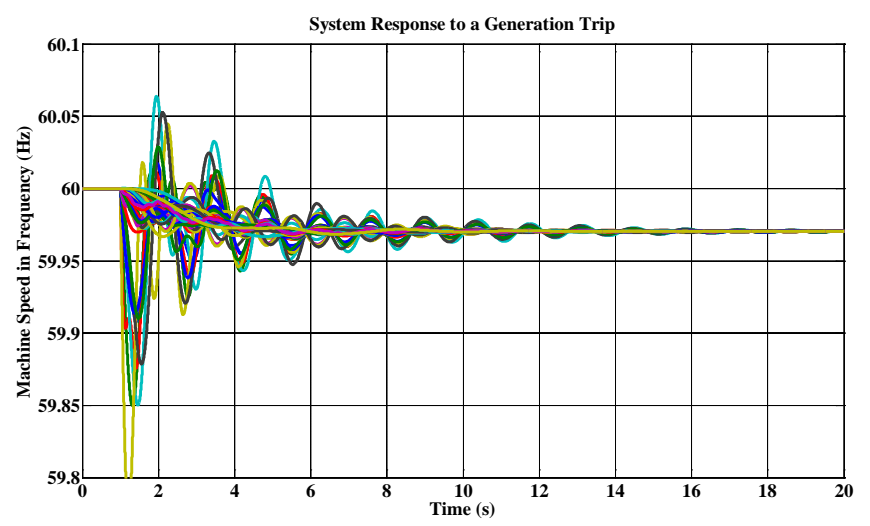

Figure 2. Machine speed deviation after a generation trip

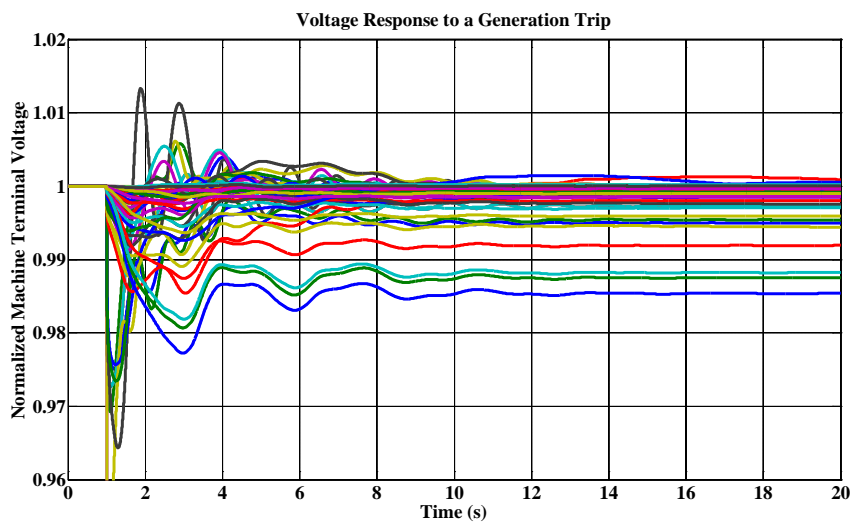

Figure 3. Machine terminal voltage after a generation trip

\section{B. Wind Case without Control}

Since the DFIG is the most widely used wind unit today, the type 3 wind model in PSS/E is employed to simulate the performance of DFIG-based wind generator in this study. In the US, it is planned to increase wind penetration ratio to $20 \%$ by 2030 [6], so the $20 \%$ penetration level is chosen to be the first wind scenario.

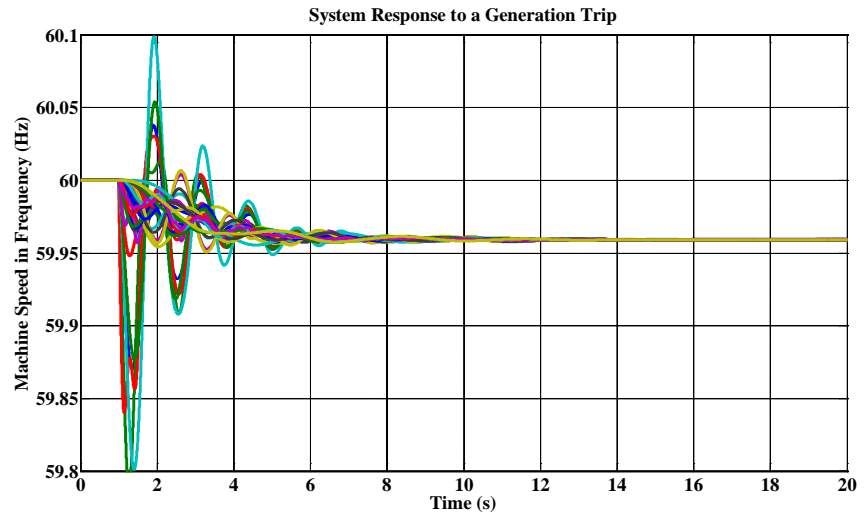

Figure 4. Machine speed deviation after a generation trip

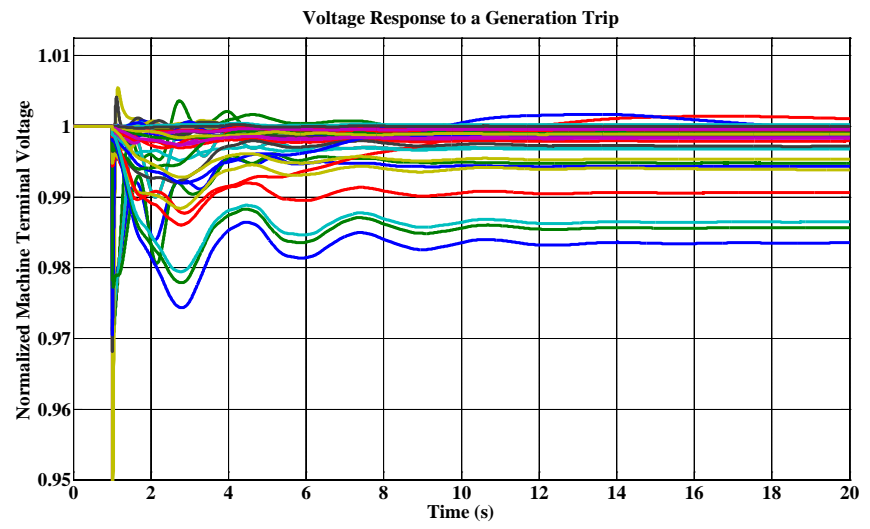

Figure 5. Machine terminal voltage after a generation trip

An approach of replacing the existing conventional power plants with wind power plants is adopted, so that the modeling study does not address any issues to the transmission 
upgrades. The wind locations are chosen based on some current and potential wind farm locations in the detailed Eastern Interconnection 2030 model. Fig. 4-5 shows the system response to a generation trip in the $20 \%$ wind case.

An extreme case of $100 \%$ renewable resources is then created to simulate the possible worst operation condition with the highest wind penetration level. Two hydro power plants involving five machines are retained in the system as there needs to be a synchronous reference in the system to ensure the simulation credibility in PSS/E, and all the rest generators are replaced by type 3 wind machines, which take about $90 \%$ of the total capacity. Fig. 6-7 shows the system response to a generation trip in the $90 \%$ wind case. As seen in Fig. 6, the frequency decline is dramatic after the generation trip event, even lower than the under frequency load shedding (UFLS) trigger, as a result of losing a majority of system inertia and turbine governors.

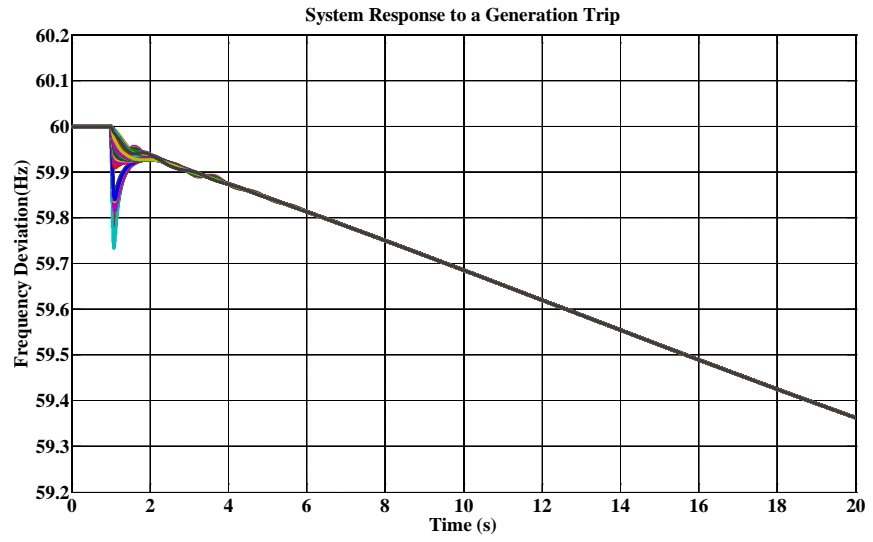

Figure 6. Frequency deviation after a generation trip

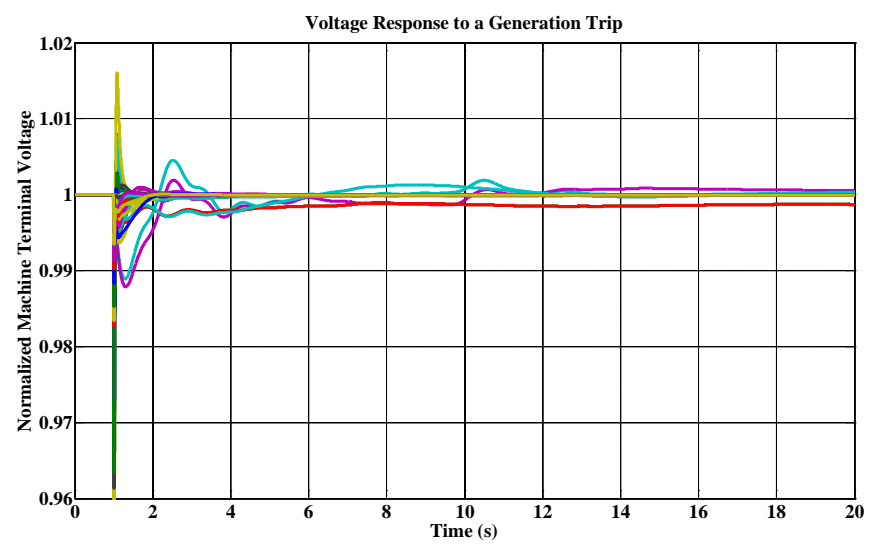

Figure 7. Machine terminal voltage after a generation trip

\section{Wind Case with Control}

In order to allow variable-speed wind generation to engage in frequency regulation, several controllers are included in the user-written electrical control model, namely wind inertia control, and wind governor control.

1) Wind Inertia Control
Wind inertia control here is of the same philosophy as GE WindINERTIA $^{T M}$ technology, whose objective is to let wind generations provide inertia response. Droop control is employed to produce temporary active power output change which is proportional to the frequency deviation and given by

$$
\Delta f=f_{m s r}-f_{\text {ref }}
$$

where $f_{m s r}$ is the measured system frequency and $f_{r e f}$ is the reference frequency. The structure of wind inertia control is shown in Fig. 8.

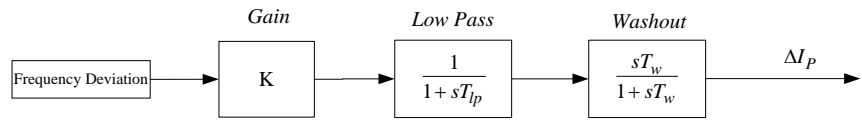

Figure 8. Wind Inertia Control Structure

\section{2) Wind Governor Control}

If working in over-speeding zone, wind turbines could decrease their rotational speed to release the reserve in seconds. Therefore, the "governor response" could be achieved on wind generation utilizing reserve. Again, droop control is used and the control structure is shown in Fig. 9.

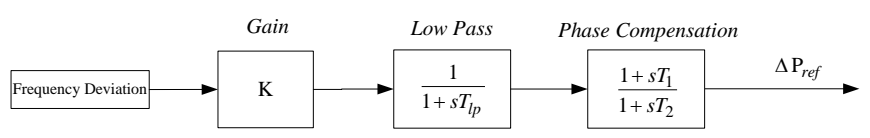

Figure 9. Wind Governor Control Structure

In the $20 \%$ wind case, two of the standard wind electric control models are replaced by a user-written model. Fig. 1011 shows the system response with wind controls in the $20 \%$ wind case, while Fig. 12-13 shows the system response with wind controls in 90\% wind case, in which 6 user-written electric control models are implemented in each area respectively.

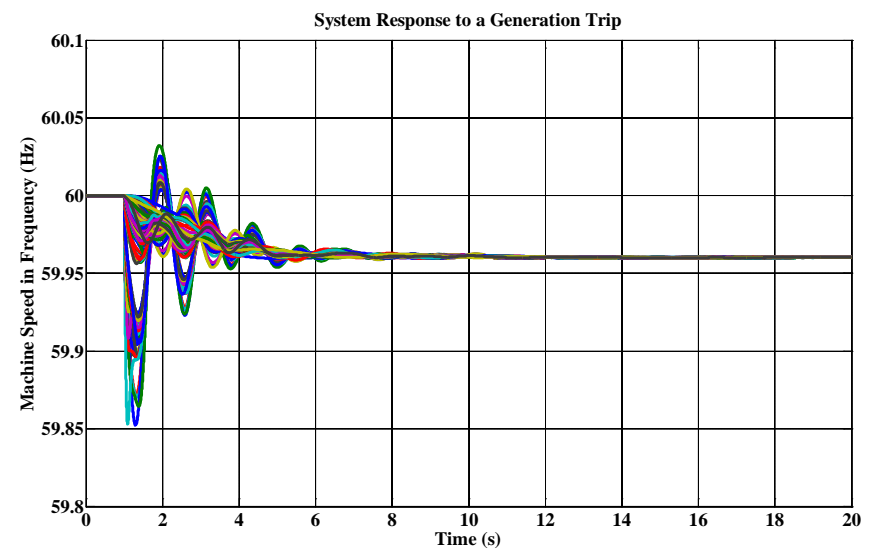

Figure 10. Machine speed deviation after a generation trip 


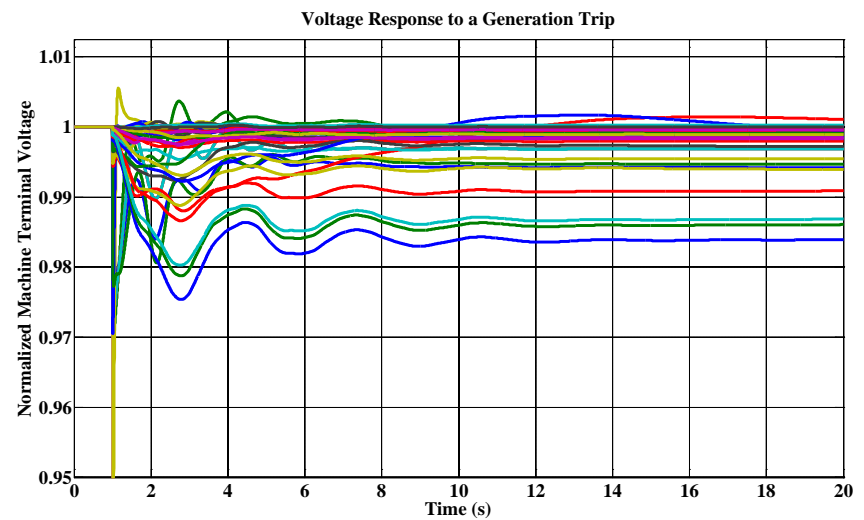

Figure 11. Machine terminal voltage after a generation trip

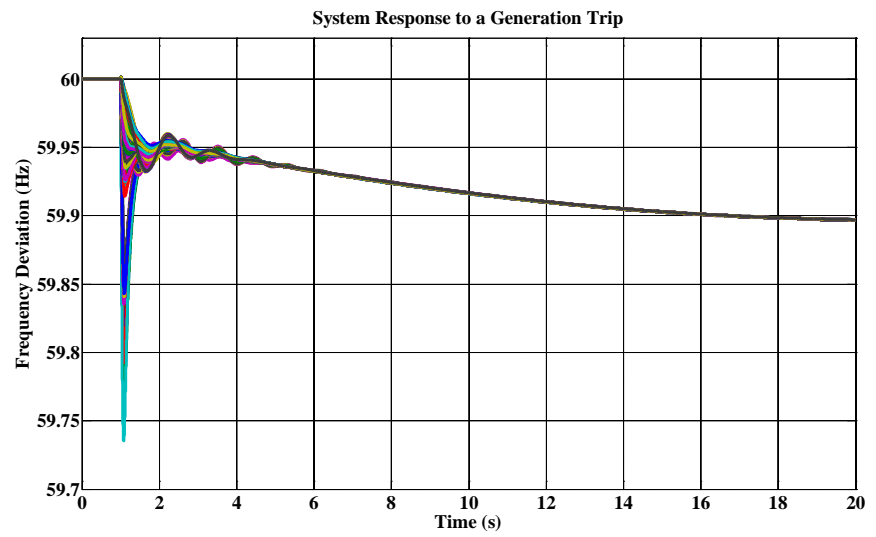

Figure 12. Machine speed deviation after a generation trip

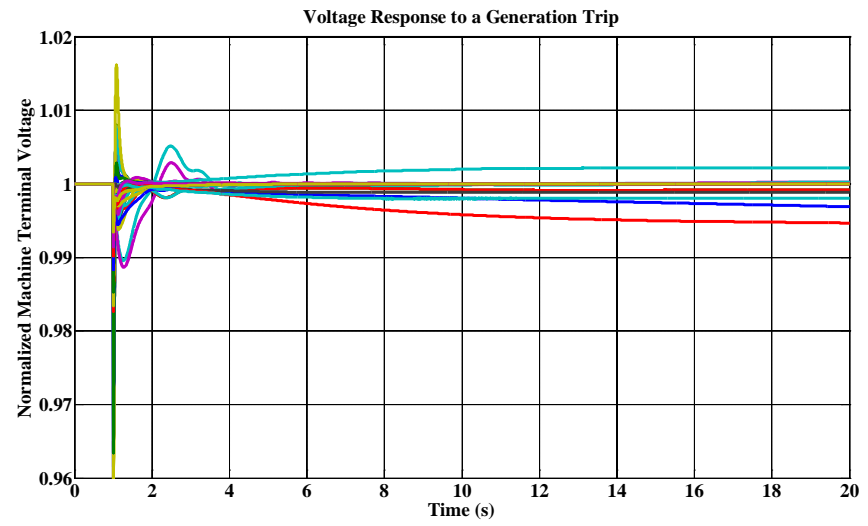

Figure 13. Machine terminal voltage after a generation trip

\section{SimULATION RESULTS COMPARISON}

\section{A. Wind Impact of System Inertial Responses}

Inertia frequency response is defined as "The power delivered by the Interconnection in response to any change in frequency due to the rotating mass of machines synchronously connected to the bulk power system, including both load and generation"[7]. As is shown in Fig. 14, both the frequency nadir and the transition time between the beginning of the disturbance and the frequency nadir are decreased with higher penetration of wind generation. It is clear that wind penetration caused the system to lose inertial response.

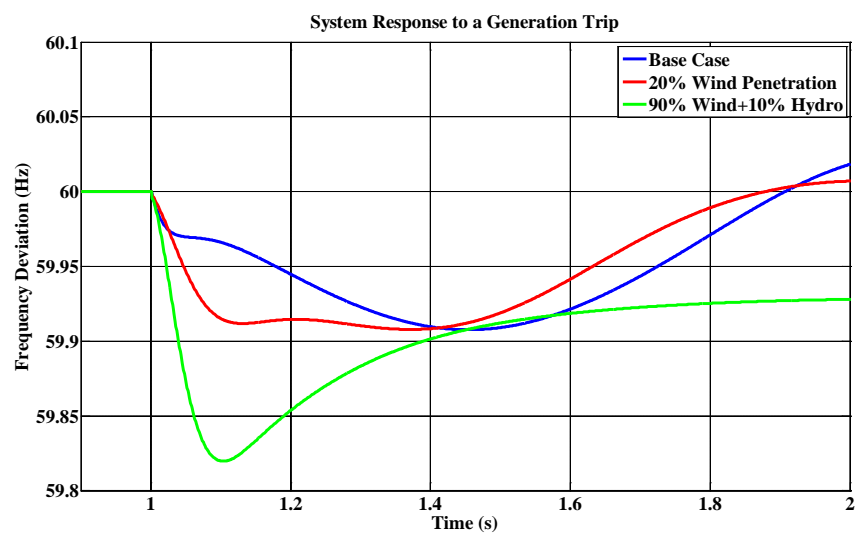

Figure 14. Frequency deviation after a generation trip under different wind penetration levels

\section{B. Wind Frequency Control}

As shown in Fig 15-18, if only with inertia control, the wind generator increases its active power temporally in several seconds following the disturbance using the kinetic energy stored in the wind blades. Apparently, this control can help reduce the frequency drop nadir. If only with the wind governor control, the wind generation would ramp up and the active power output increases proportional to the frequency deviation, which is typical "governor response". With both the wind inertia and governor control, the frequency nadir will be reduced further and the steady state frequency also decreases.

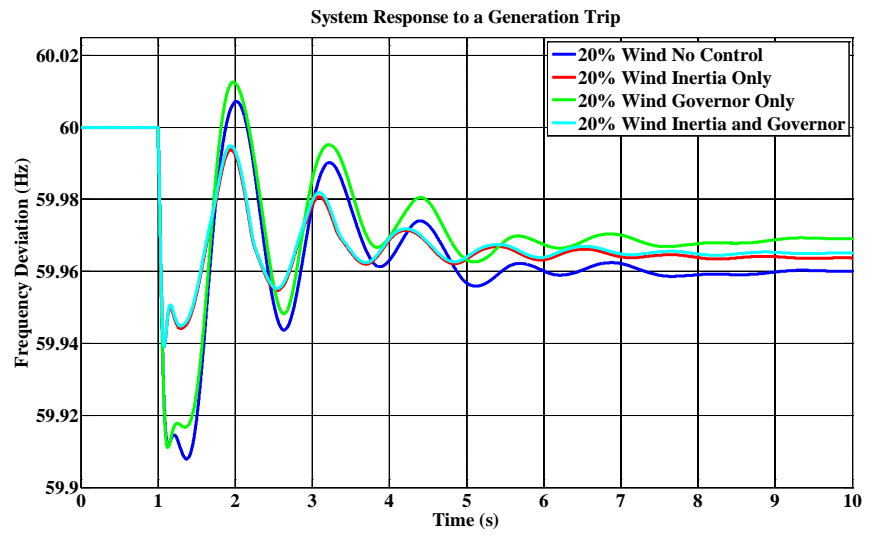

Figure 15. Frequency deviation after a generation trip with different controls

Fig. 15-16 shows the frequency deviation and active power output of the $20 \%$ wind penetration level. In this case, as the conventional generators and their governor response are still dominant in the system, the settling frequency after the disturbance is not changed significantly. However, in the $90 \%$ wind case, the wind control can bring the frequency back to steady state without triggering the UFLS. 


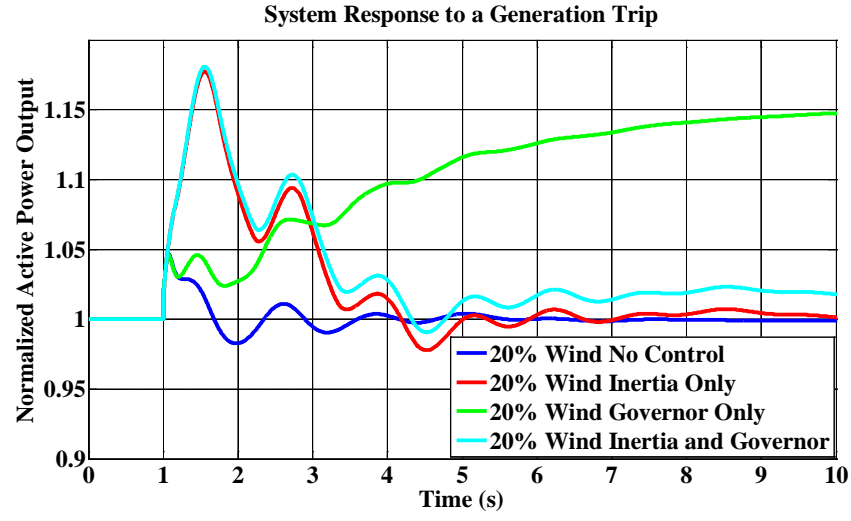

Figure 16. Active power output after a generation trip with different controls

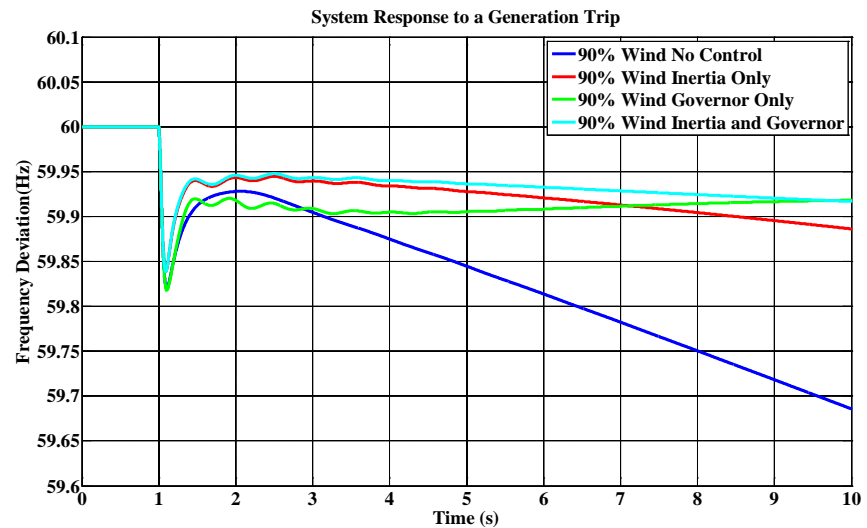

Figure 17. Frequency deviation after a generation trip with different controls

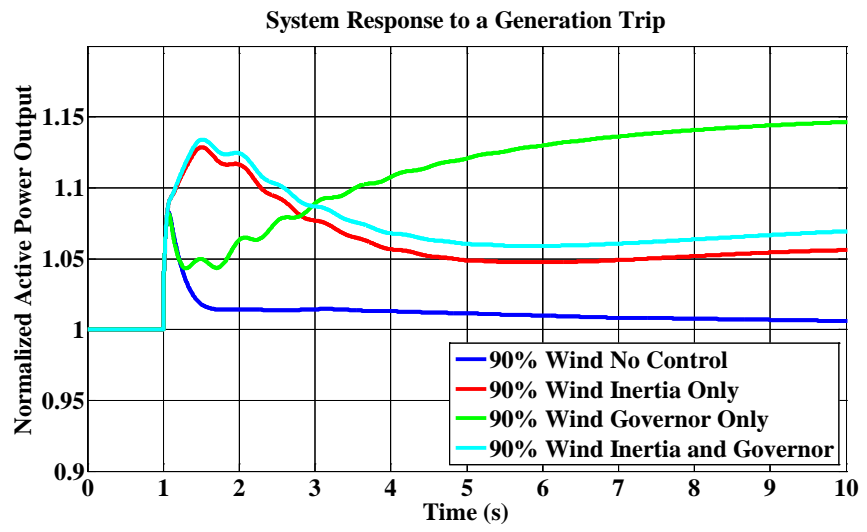

Figure 18. Active power output after a generation trip with different controls

\section{CONCLUSION}

In this paper, several simulation cases of the NPCC system are developed to investigate the high wind penetration impact to NPCC system. A PSS/E user-defined electric control model was employed to implement fast active power controls, including wind inertia control and wind governor control. As demonstrated by the simulation results comparison, wind generation penetration decreases the system inertia significantly, and the controlled wind generation effectively contributes to the frequency regulation. Although the wind inertia control adopted in this paper only improve the response of frequency nadir, it can be further developed to respond to both frequency deviation and the time derivative of the frequency deviations, which will be addressed in future work. The simulation results provide insight in designing and operating wind generation active power control to an interconnected power system. Moreover, considering the fact that many bulk power systems around the world may have similar high wind penetration profiles, the control strategies discussed in this paper holds great potential.

\section{ACKNOWLEDGMENT}

This work was supported primarily by the Engineering Research Center Program of the National Science Foundation and DOE under NSF Award Number EEC-1041877 and the CURENT Industry Partnership Program.

\section{REFERENCES}

[1] Y. Zhang et al., "Role of wind power in the primary frequency response of an interconnection," National Renewable Energy Laboratory (NREL), Golden, CO, USA, Oct. 2013.

[2] N.W. Miller, K. Clark, and M. Shao, "Impact of frequency responsive wind plant controls on grid performance," In Proc. 9th International Workshop on Large-Scale Integration of Wind Power, Quebec, Canada, Oct. 2010.

[3] R. G. de Almeida and J. A. P. Lopes, "Participation of doubly fed induction wind generators in system frequency regulation," IEEE Transactions on Power Systems, vol. 22, no. 3, pp. 944 - 950, Aug. 2007.

[4] Joseph $\mathrm{H}$ Eto et al., "Use of frequency response metrics to assess the planning and operating requirements for reliable integration of variable renewable generation,” Ernest Orlando Lawrence Berkeley National Laboratory, Berkeley, CA, LBNL-4142E, December 2010.

[5] http://en.wikipedia.org/wiki/Northeast_Power_Coordinating_Council

[6] CBS, "On Earth Day, Obama Talks Up Wind Power", http://www.cbsnews.com/2100-205_162-4961315.html

[7] NERC Frequency Response Initiative, April, 2010f 